\title{
Investigation on the plasticity accumulation of Ti-6Al-4V fretting wear by decoupling the effects of wear and surface profile in finite element modelling
}

\author{
A.L. Mohd Tobi ${ }^{a^{*}}$, W. Sun ${ }^{\text {b }}$, P.H. Shipway ${ }^{\mathrm{b}}$ \\ *abdlatif@uthm.edu.my \\ ${ }^{a}$ Structural and Integrity Monitoring Research Group, \\ Faculty of Mechanical and Manufacturing Engineering, \\ Universiti Tun Hussein Onn Malaysia, Batu Pahat, Malaysia. \\ ${ }^{b}$ Faculty of Engineering, University of Nottingham, \\ University Park, Nottingham, NG7 2RD, UK. \\ Received Date Line
}

\begin{abstract}
A finite-element-based wear modelling methodology and a computational device for decoupling wear effects is presented in this study. The decoupling of wear effects facilitates the capture of plasticity accumulation on a particular wear-scarring profile after a specific number of cycles. It was determined that significant plasticity accumulation due to plastic shakedown was predicted in a partial-slip case, while a saturation of plastic deformation was predicted in a gross-sliding case. It was also predicted that a significant amount of plasticity does not meaningfully contribute to the stress and strain range observed in the contact region. It was assumed that plasticity accumulation contributes towards wear of the material and feeds the stress changes, which indirectly affects fatigue life.
\end{abstract}

Keywords: Finite element; Fretting wear; Ti-6Al-4V; Plasticity. 


\section{Introduction}

Fretting is a mechanical problem that arises from small repetitive motion between the surfaces of two elements in a contact pair. The amount of displacement that occurs during fretting can range from a few nanometres to a few hundred micrometres [1]. The actual causes of failure at the contact region are attributed to induced cyclic loading and/or wear on the contact region. The onset of fretting was originally studied by Catteneo [2] and independently by Mindlin [3], based on contact with Hertzian geometry under normal and tangential loads

[4]. Full sliding (gross-sliding) between the contact surfaces will occur if the total tangential traction, $Q$, between the surfaces is greater than the limiting frictional force. This effect can be described by the relation, $Q>\mu P$, where $P$ is the normal load between the bodies, and $\mu$ is the coefficient of friction. Partial-slip contact occurs below the limiting value.

The partial-slip contact surface is divided into two distinct regions: a central stick zone $|x|<c$, and a slip zone $c<|x|<a$ where $x$ is the horizontal position on the contact surface. $c$ represents the central stick zone and $a$ represents the half contact width of the contact area. In many applications (e.g. contacts subject to vibration), the tangential force varies cyclically with time. The stress fields for partial-slip can be obtained by careful superposition of reversed tangential force elliptical distribution, resulting in the new stick zone $|x|<b$ from the reverse cycle. Please refer to Fig. 1 for an illustration [5].

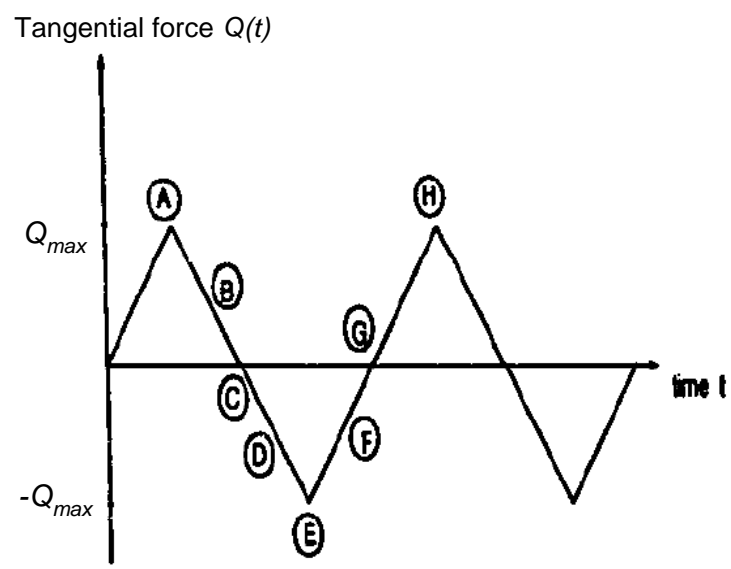



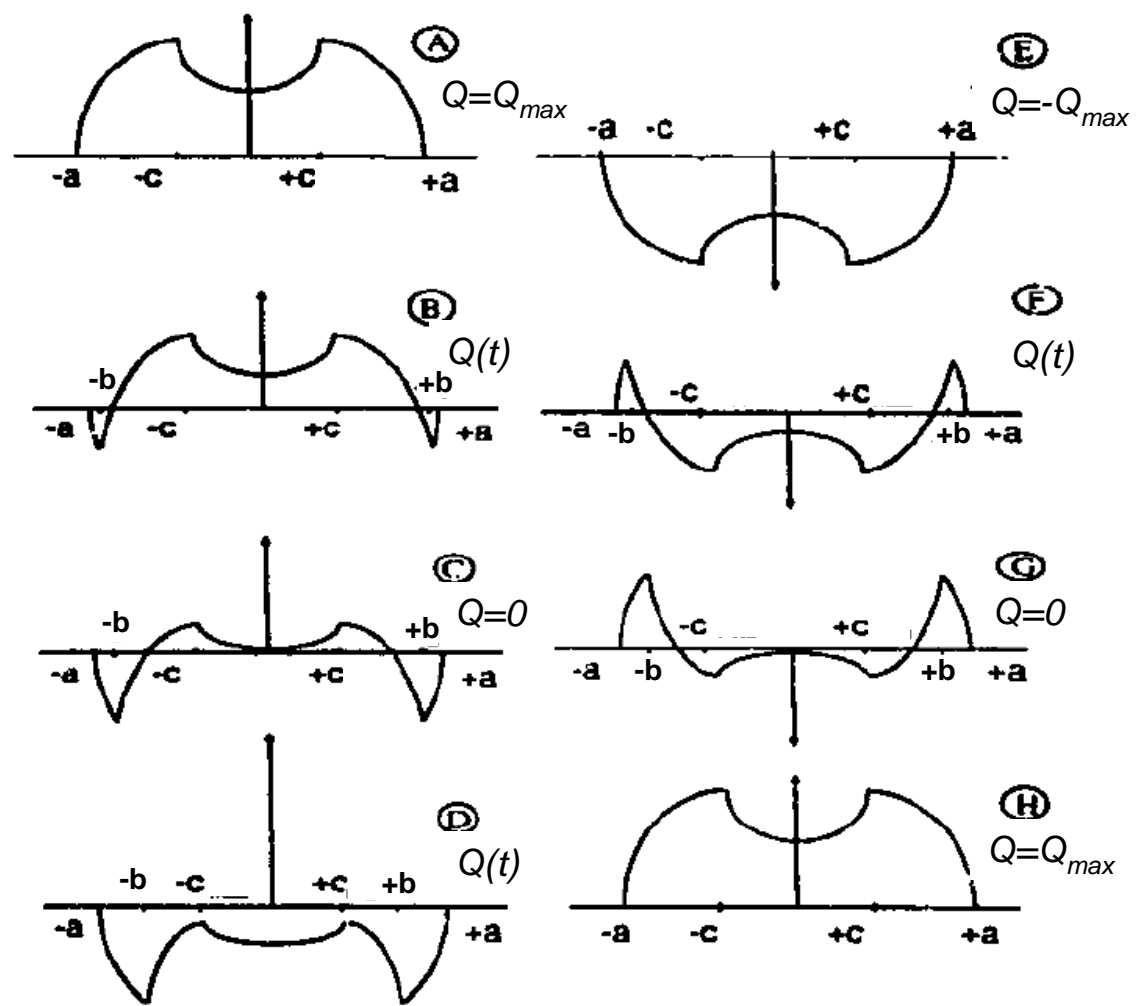

Fig. 1. Partial-slip loading cycle and the corresponding shear traction distributions, after [5].

Fretting fatigue is commonly experienced in partial-slip contact because the stress concentration site develops between the slip and stick zones. A reduction in fatigue life results from accelerated crack growth in this regime. In the case of gross-sliding, slip occurs across the entire contact region. Fretting wear is characterised by severe surface damage by wear followed by an overall reduction in contact stresses due to contact conformity [6].

A finite element analysis of fretting behaviour can be used to increase the understanding of fretting wear and fatigue test results, and also provide an enhanced foundation for behavioural predictions. An approach involving an incremental wear simulation was developed by McColl et al. for a cylinder on flat arrangement. The approach used a modified Archard wear equation (including experimental validation), which was applied differentially in terms of contact pressure and slip, on a nodal basis to incorporate material removal effects [7]. Similar concepts were applied in [8] using an energy-based wear model. Previous attempts to model fretting wear have been conducted by implementing the cycle jump technique. This technique involves the use of a single cycle in the model to represent $N$ number of cycles of fretting wear [7, $9 \& 10]$. This has been done due to limited computational capability and assuming that the incremental wear depth is similar throughout the cycle jump.

Ding et al. investigated the evolution of elastic stress and strain distributions with fretting wear [9]. The major effect of gross-sliding fretting is the rapid decay of contact stresses. This occurs because of the wearinduced contact pressure redistribution, which is the result of the widening of the wear scar. In contrast, for the partial-slip case, the corresponding direct and shear stresses are predicted to increase and concentrate at the stick- 
slip interface. Research dedicated to the modelling of fretting wear with plasticity behaviour was first introduced by Mohd Tobi et al., using linear kinematic hardening of Archard-based wear on titanium alloy Ti-6Al-4V [10]. It was determined that plasticity will accumulate, similar to the ratchetting phenomenon, which suggests a possibility of interaction between cyclic plasticity with wear formation, and crack initiation.

Wear modelling based on plasticity behaviour has improved understanding of the evolution of wear and damage in fretting contact [10-13]. Works have involved on wear behaviour [10], to fatigue damage prediction [12 \& 14], crystal plasticity model [15], and energy quantification [16]. The major finding from the research conducted in [13] was that the stick region in the partial-slip case became smaller as wear increased. However, with elastic behaviour, the saturation of the stick region caused infinitely high contact pressure, which is impossible.

Garcin et al. [17] studied the effect of wear and damage accumulation due to fretting wear under elastic conditions. The author found that the crack nucleation region in the gross-sliding case decreased with an increased wear rate. For the partial-slip case, the crack nucleation region was unaffected by the wear rate because the frictional dissipation energy was small, as a result of the small displacement amplitude. Gandiolle \& Fouvry [14] compared the effect of elastic-only and elastic-plastic behaviour in crack nucleation and crack propagation on the fretting fatigue of $316 \mathrm{~L}$ stainless steel. It was expected that the crack nucleation and crack propagation predictions based on the elastic-plastic fracture mechanics approach would be closer to the experimental results than the elastic behaviour prediction. The elastic-only prediction was found to be overly conservative in regard to the prediction of crack nucleation and propagation.

This study investigates the prediction of plasticity accumulation as the effect of simulated incremental wear. In addition, the effect of the surface profile generated by the wear is separated in order to develop an understanding of the plasticity accumulation in fretting wear modelling based solely on its geometrical surface profile shape. A finite-element-based wear modelling methodology, along with a computational device that facilitates the capture of plasticity accumulation on a particular profile of wear scar at a specific number of cycles, is presented in this study. The plastic accumulation predicted by the analysis is quantified and the Smith-WatsonTopper (SWT) fatigue life parameter is calculated. 


$$
\frac{V}{S}=K \frac{P}{H},
$$

where $V$ is the total wear volume, $S$ is the sliding distance, $K$ (dimensionless) is the wear coefficient, $P$ is the normal load, and $H$ is hardness of the material.

In order to simulate the evolution of wear along the contact surface using wear cycles, the wear must be calculated locally for a specific point on the contact surface. For a given individual (nodal) point on the contacting surface (in the FE model), Eq. (1) can be expressed in terms of the local wear depth increment, $d h$, over the increment of local slip, $d S$, as follows [18]:

$$
\frac{d h}{d S}=k_{1} p(x),
$$

where $K / H$ from Eq. (1) is replaced by $k_{1}$, a local wear coefficient. Owing to our inability to measure this local wear coefficient, one approach is to assume that a bulk wear coefficient, $k$, which is measured across the complete contact width, can be employed. This bulk wear coefficient can be determined from the measured wear scar [7] using the following equation:

$$
k=\frac{W b h_{m}}{4 \delta_{\text {actual }} \times N_{t} P},
$$

where $W$ is the wear scar width, $b$ is the width of the flat specimen, $h_{m}$ is the average wear scar depth on the $x$ coordinate axis, and $N_{t}$ is the total number of fretting fatigue cycles. The $W b h_{m}$ term is the estimated total wear volume, $V_{\text {exp }}$, of the flat specimen. The rationale adopted in this study follows a combined experimentalcomputational methodology to arrive at an average local wear coefficient, $\bar{k}$. The averaging is affected with respect to the spatial-temporal evolution of the contact interface geometry, as described in [10], and uses the bulk wear coefficient, $k$, as an initial estimate for $\bar{k}$ (i.e. both over the number of cycles and across the contact width, thus averaging with respect to contact pressure and relative slip over the evolution of the wearing contact).

McColl et al. further developed Eq. (2) in order to simulate the material removed due to fretting wear in a finite element simulation [7]. A modified Archard equation that defines the incremental wear depth, $\Delta h$, for a specific point, $x$, experiencing an incremental slip, $\delta$, and pressure, $p$, at specific time, $t$, is thus given as:

$$
\Delta h(x, t)=\bar{k} p(x, t) \delta(x, t)
$$


Owing to computational limitations, the wear simulation cannot model individual wear cycles. Therefore, a cycle jump technique was used and the method developed in [7, $9 \& 10]$ was followed. This technique applies the wear corresponding to a cycle jump of $\Delta N$ cycles in increments during a single simulated fretting cycle. Therefore, by multiplying Eq. (4) with the cycle jump, $\Delta N$, the wear corresponding to $\Delta N$ cycles can be simulated in one simulated fretting cycle. Eq. (4) can now be presented with respect to time, $\tau$, within one cycle corresponding to $\Delta N$ wear cycles, as follows:

$$
\Delta h(x, \tau)=\Delta N \bar{k} p(x, \tau) \delta(x, \tau)
$$

The wear determined by the modified Archard equation was implemented in the analysis using an adaptive mesh technique via the UMESHMOTION user subroutine within ABAQUS (Version 6.11). The adaptive meshing algorithm in ABAQUS applies the local wear increment for all surface nodes in two steps. First, the local wear increment is applied by moving the surface nodes in the local normal direction. This geometry update is executed purely as an Eulerian analysis. Secondly, the material quantities (variables) are remapped to the new positions by advection. This is accomplished by solving the advection equations using a second-order numerical method called the Lax-Wendroff method. ABAQUS accounts for the remapping of the residual plastic strain with simulated wear. These two steps cause an equilibrium loss that is corrected by solving the last time increment of the contact problem [10].

A similar method has also been employed by [17]. The current method of adaptive meshing will remap the variable values, including the plastic strains. It is important to note that at this current stage, it was assumed that the subsequent plastic strain prediction was based on continuity from the remapped variable, as described in the methodology. A more advanced wear model that includes the effect of plastic strain release should be developed in future to achieve a more realistic simulation of fretting wear. The wear analyses simulate up to $300 \times 10^{3}$ cycles, using a cycle jump $\Delta N$ of $3 \times 10^{3}$, with 100 increments in one simulated tangential fretting cycle. For gross-sliding and partial-slip tests in the present work, the resulting values of $\bar{k}$ are $8.5 \times 10^{-9} \mathrm{MPa}^{-1}$ for grosssliding and $4.5 \times 10^{-8} \mathrm{MPa}^{-1}$ for partial-slip [10].

Recently published work on fretting wear modelling with plasticity, either in wear prediction or cracking prediction, has not encountered the issue of plastic strain release [12 \& 13]. The experimental results show good agreement with the wear prediction. The only difficulty that has not yet been overcome is the prediction of the shape of the wear scar. This study is trying to highlight the mechanism by which the plasticity is introduced with active interaction between the effect of geometrical changes with wear.

Thus, in order to make progress towards improving wear prediction, this study seeks to distinguish between plasticity that is accumulated due to worn geometrical profiles, and plasticity that accumulates due to the effects of increasing wear depth caused by the wear model. The author has conducted preliminary wear modelling for a gross-sliding case with $\Delta N=1$ up to 100 cycles. The model predicted that the plasticity accumulation at the central contact region would saturate after five cycles, and it also predicted that there would be an increase in 
equivalent plastic strain at the contact edge. This corresponds to the edge effect generated from worn geometry. This model suggests a trend that is qualitatively similar to the trend predicted in the research conducted in [10]. For the partial-slip case, no plasticity accumulation was predicted at the end of 100 cycles when $\Delta N=1$ was used, since the peak pressure at the stick-slip interface was not developed yet.

\subsection{FE model}

Fig. 2 shows the gross-sliding and partial-slip FE models for the cylinder on the flat fretting specimen. These meshes were arrived at through an iterative process in order to achieve a compromise between (i) the accuracy of the predicted surface and subsurface variables, (ii) reasonable CPU times for incremental wear simulations, and (iii) the capacity to cater for wear-induced increases in contact width. Plane strain, linear quadrilateral elements were employed in the analysis due to their reliable contact performance, as second order elements can give fluctuating pressure distributions for frictional contact problems [10].

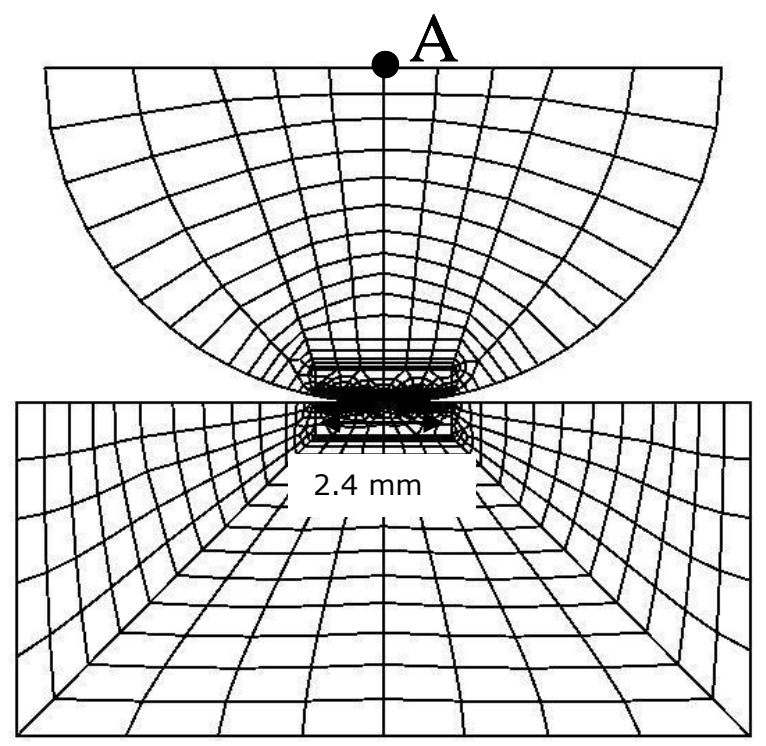

a)

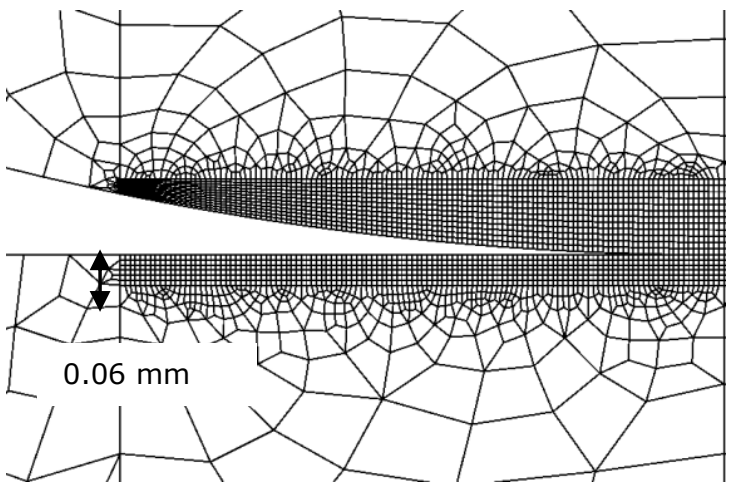

b) 

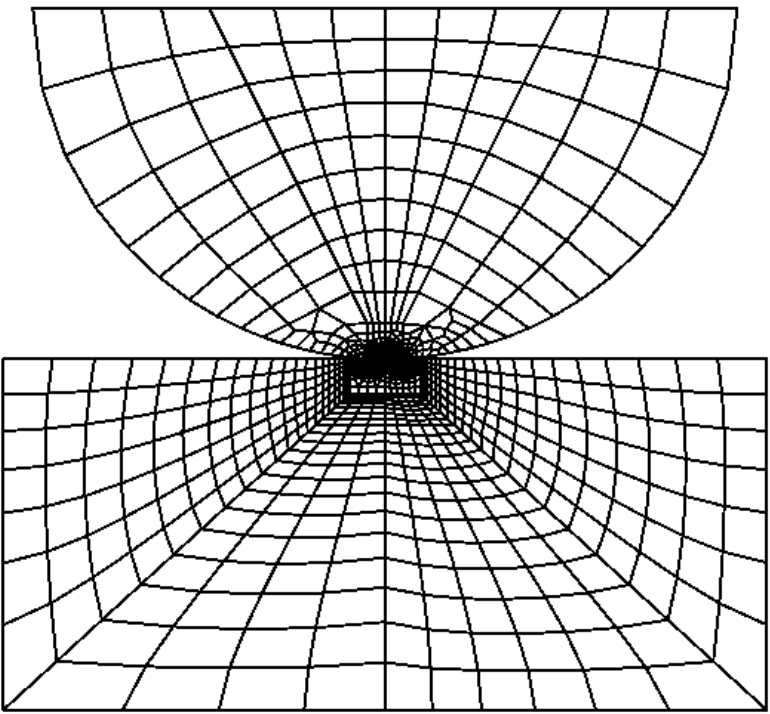

c)

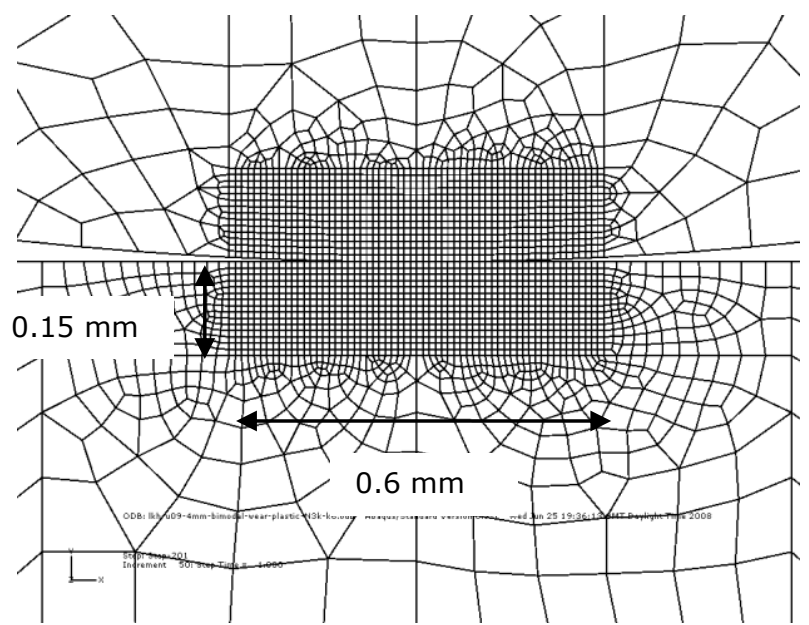

d)

Fig. 2. Mesh details for a) full model for gross-sliding, b) contact region detail for gross-sliding, c) full model for partial-slip and d) contact region detail for partial-slip, after [10].

Contact interaction between the cylinder and the flat surface was defined by using a finite sliding-contact-pair algorithm. This algorithm established the relationship between the master nodes on the cylinder contact surface and the slave nodes on the flat contact surface. The maximum allowable penetration depth $(h$-crit) between the slave and master nodes during the iterative solution process was defined to equal $1 \mu \mathrm{m}$. The minimum allowable distance between the initial coordinates of the adjacent nodes on the mating contact surfaces (ADJUST parameter) was set to $0.001 \mu \mathrm{m}$. In order to improve the stress resolution while maintaining a reasonable computational time, the mesh size was gradually refined towards the contact regions, as shown in Fig. 2. The element size in the contact region was approximately a $10 \mu \mathrm{m}$ square, and the transition from a fine to coarse mesh was achieved via the mesh control algorithm in ABAQUS. Coulomb friction is employed based on the Lagrange multiplier contact algorithm. It was used to ensure the exact stick condition when the shear stress is less than the critical shear value according to the Coulomb friction law. A 0.9 coefficient of friction was applied to the contact surface, and was based on the stabilised gross-sliding values from [10].

The elastic material properties used for the cylinder and the flat surface include a Young's modulus of 115 GPa and a Poisson's ratio of 0.342 . The kinematic hardening model is a simplified representation used to model this effect. In this study, the plasticity data used to model Ti-6Al-4V cyclic plastic behaviour was obtained from [19]. A yield stress, $\sigma_{y}$, of $840 \mathrm{MPa}$ and a hardening modulus, $c$, of $7.32 \mathrm{GPa}$ were employed. The results of the wear modelling were validated with the published work by [10] under the same conditions and wear modelling. 


\subsection{Novel fretting wear model extension}

A new FE fretting model was created once the original FE wear model was completed. This new model used the state variables, loading conditions, and the updated geometrical shape generated from the initial FE wear model at the end of every $N_{i}^{\text {th }}$ number of cycles required for the remodel analysis (Fig. 3). Five new models were created from the recorded state variables, representing loading conditions at the $0^{\text {th }}, 15,000^{\text {th }}, 75,000^{\text {th }}, 150,000^{\text {th }}$, and $300,000^{\text {th }}$ cycle.

An additional five cycles of fretting were then simulated for each of the models without wear modelling. It is important to note that the new FE model will not experience the effects of the active wear model, since the wear subroutine is not included in the new model. However, the new model will have the same worn shape, stresses, strains, and loading conditions generated during the initial wear modelling process. This will allow the new model to predict the amount of plasticity accumulation due to its worn geometrical and state variable conditions, without being subjected to the effects of active wear simulation. The flowchart of the new fretting wear model extension methodology in addition to the initial wear modelling, is shown in Fig. 3. 


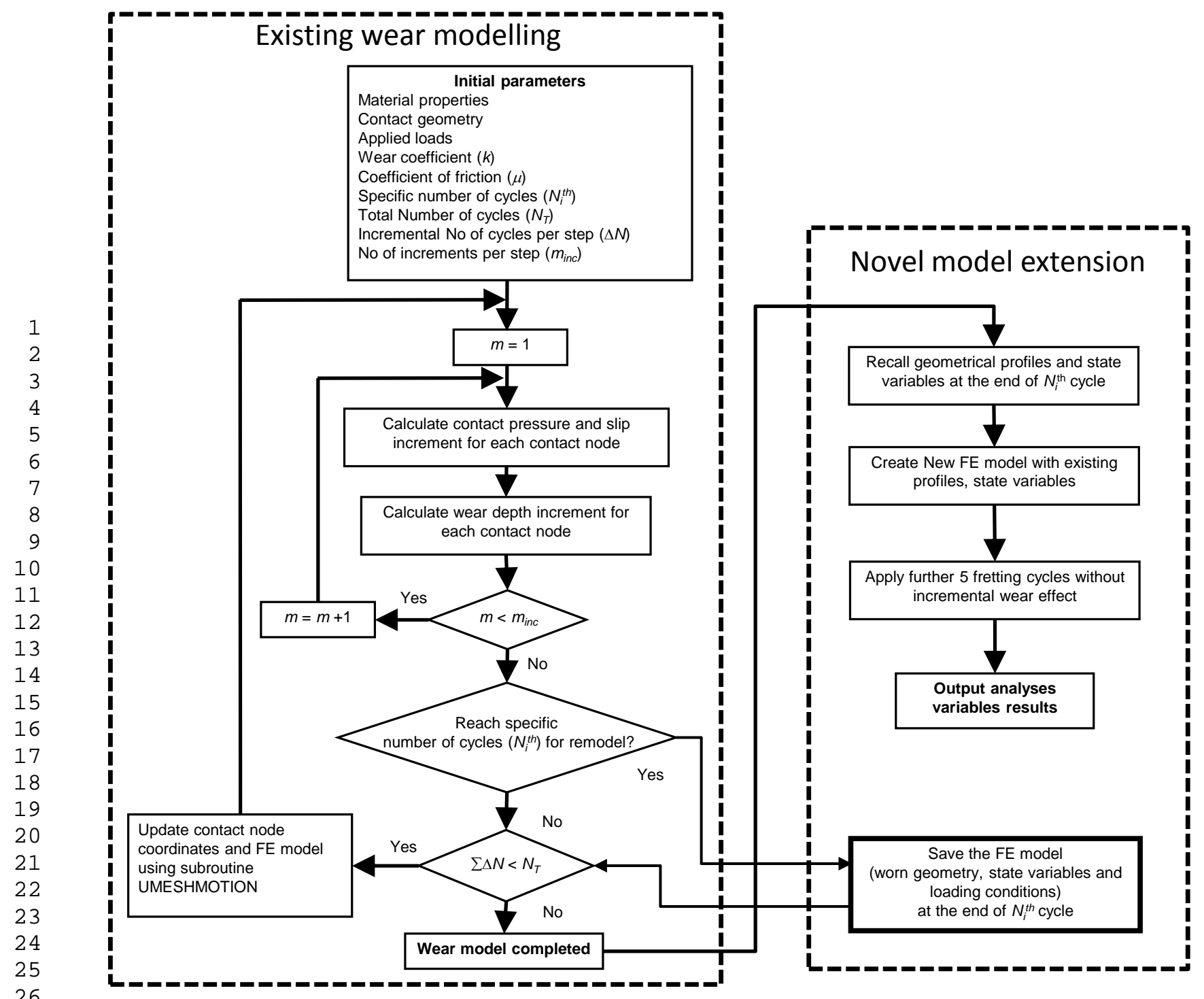

Fig. 3. Flowchart illustrating FE-based incremental wear simulation methodology in ABAQUS with the new fretting model extension.

The purpose of this study is to further discuss the results presented by the author in [10] and to study the effects of plasticity deformation on the wear profile and stress distribution in the contact region. There are two points in the article that merit further discussion. First, even though the plasticity behaviour is modelled, the predicted wear profile for the gross-sliding case predicted a $U$-shaped wear profile instead of the $W$-shaped profile that was observed experimentally. The second point is that a determination needs to be made as to whether plasticity accumulation contributes to wear development, or whether wear development contributes to plasticity accumulation.

As a result, this study preserved the method that has been presented in [10] while separately assessing the accumulation of plasticity when the wear simulation is being decoupled. This study aims for future research to build on the results from this research and develop a new wear model that correlates the effect of the plasticity 
accumulation to be derived and applied without cycle jump on the first attempt. It is expected that the formation of the $W$-shaped wear scar that was observed experimentally [10] can be predicted.

\section{FE results}

\subsection{Wear modelling results}

\subsubsection{Gross-sliding case}

The results of the wear modelling analysis (up to 300,000 cycles) for the gross-sliding case are presented in Fig. 4. The contact pressure distribution is shown in Fig. 4a. This value is taken as the contact passes through the centre of the contact. A reduction in pressure is predicted (Fig. 4a) as the contact becomes conforming, as evidenced from the evolution of the flat specimen wear profile shown in Fig. 4b. For the equivalent plastic strain prediction (Fig. 4c), the central region experiences a sudden increase in plastic strain, close to $0.25 \%$ at the $15,000^{\text {th }}$ cycle, before subsequently reducing with further wear cycles. This is due to central region wear, which removes the residual plastic strain as it wears down. The development of plasticity at the contact edge is due to the edge effect plasticity, as explained in [6 \& 10]. The results are validated with the FE modelling performed by [10], which show the same results under the same conditions.

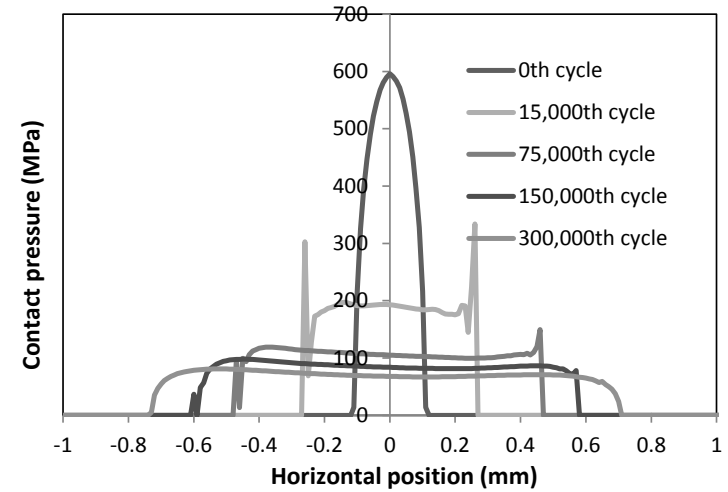

(a)

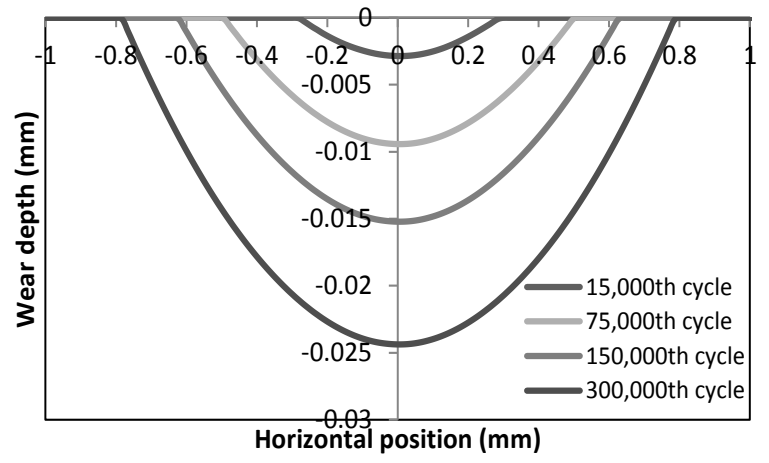

(b)

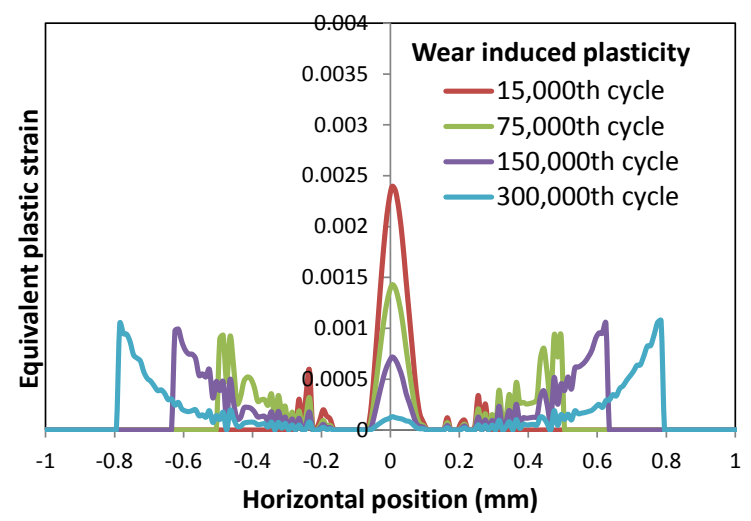

(c)

Fig. 4. FE-predicted wear-induced evolution for the gross-sliding case up to 300,000 cycles $\left(2 \delta_{a p p}=120 \mu \mathrm{m}, P=1000\right.$ 


\subsubsection{Partial-slip case}

Figs. 5(a-c) show the wear modelling results up to 300,000 cycles for the partial-slip case. The contact pressure distribution (Fig. 5a) shows the development of peak pressure up to the $75,000^{\text {th }}$ cycle before a near Hertzian-like shape develops at the $300,000^{\text {th }}$ cycle. The values are taken as the contact passes through the centre of the contact. The predicted wear profile is shown in Fig. 5b. Typical wear depth was developed at the slip region, and there was a reduction in the stick region as the wear increased. For the predicted equivalent plastic strain distribution (Fig. 5c), it is clearly shown that a significant amount of plasticity was predicted (up to 200\%) at the stick-slip interface as the wear increases. Similar results were predicted in [10].
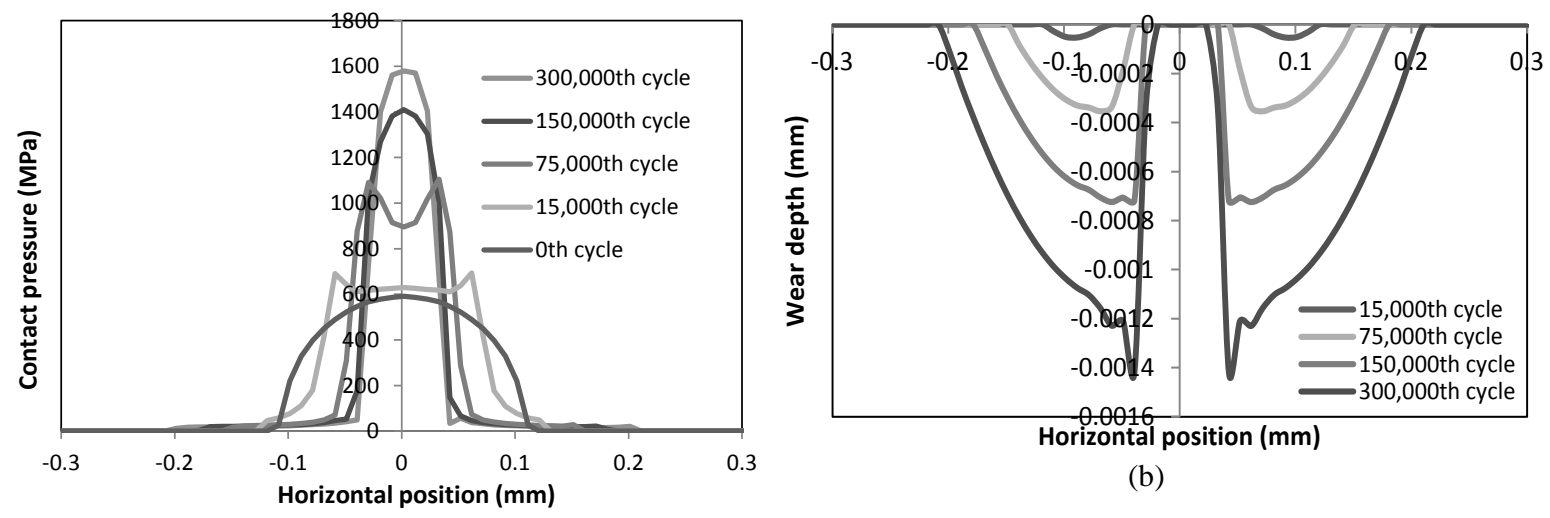

(a)

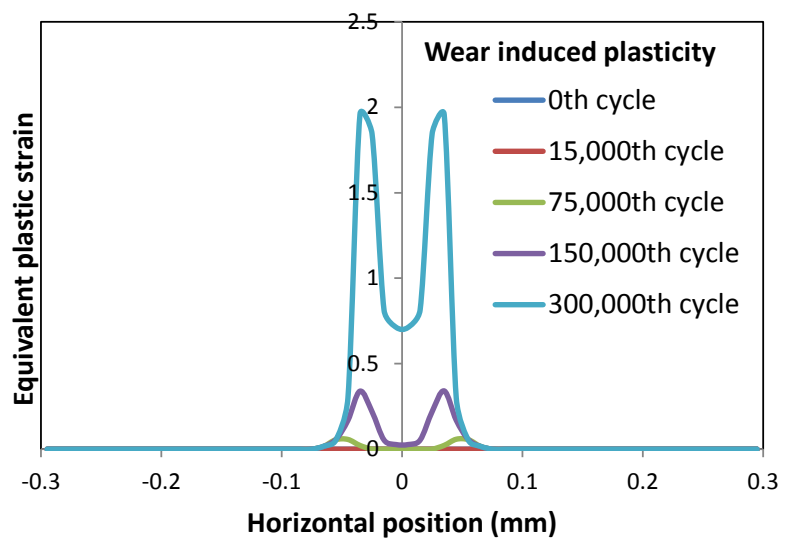

(c)

Fig. 5. FE-predicted wear-induced evolution for partial-slip case up to 300,000 cycles $\left(2 \delta_{a p p}=50 \mu \mathrm{m}, P=1000 \mathrm{~N}\right)$; a) contact pressure, b) wear profile, and c) equivalent plastic strain.

\subsection{New model extension results}

\subsubsection{Gross-sliding case}


The equivalent plastic strain results for the new extension model in the gross-sliding case are shown in Figs. $6(\mathrm{a}-\mathrm{e})$ at the $0^{\text {th }}, 15,000^{\text {th }}, 75,000^{\text {th }}, 150,000^{\text {th }}$, and $300,000^{\text {th }}$ cycle. The distribution plots are shown after zero, one, and five additional cycles of simulated fretting contact without the wear effect. At the $0^{\text {th }}$ cycle (Fig. $6 a)$, with one additional fretting cycle, the plastic strain builds up significantly at the central region of the contact, close to $0.3 \%$ value. With further simulated fretting cycles, no significant increase in plastic strain was predicted.

At a higher number of cycles, with additional simulated fretting cycles, the accumulation of plasticity can only be seen on the left side of the contact edge. The reason for that is due to the less worn profile generated by the wear modelling. The contact will travel farther on the right side of contact, since the first fretting wear cycle model is moving to the right from the central position and stops at the far left of contact. This movement is exaggerated further with the cycle jump implemented during the wear modelling, and causes the left wear scar edge to have a shallower surface profile and greater surface discontinuity than the right side. The residual plastic strains generated from the wear modelling are present in the new extension model at zero additional cycles. Increases in plastic strain are predicted after one additional cycle for the $15,000^{\text {th }}, 75,000^{\text {th }}, 150,000^{\text {th }}$, and $300,000^{\text {th }}$ cycles. For the subsequent additional fretting cycles, there is no predicted increase in plastic strain for the $300,000^{\text {th }}$ cycle case (Fig. 6e). Comparing the magnitude of the increase in plastic strain between the $15,000^{\text {th }}$, $75,000^{\text {th }}$, and $150,000^{\text {th }}$ cycle after five additional cycles, it can be seen that the plastic strain increase rate is growing from the $15,000^{\text {th }}$ to the $75,000^{\text {th }}$ cycle, but decreasing for the $150,000^{\text {th }}$ cycle. Only the first additional cycle shows an increase in plastic strain for the $300,000^{\text {th }}$ cycle case (Fig. 6e).

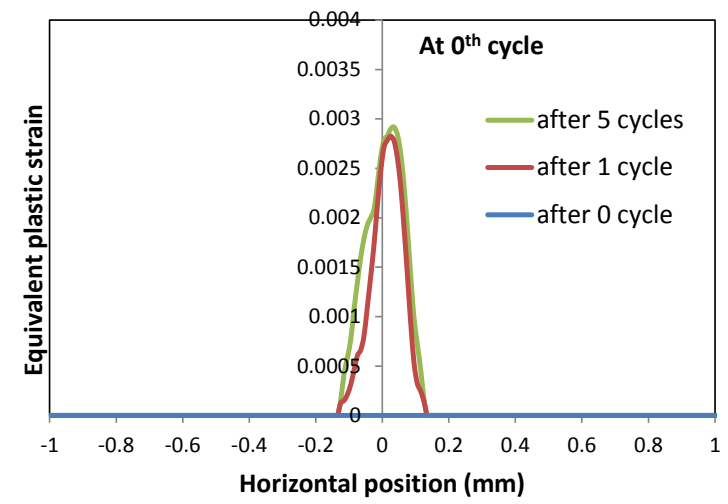

(a)

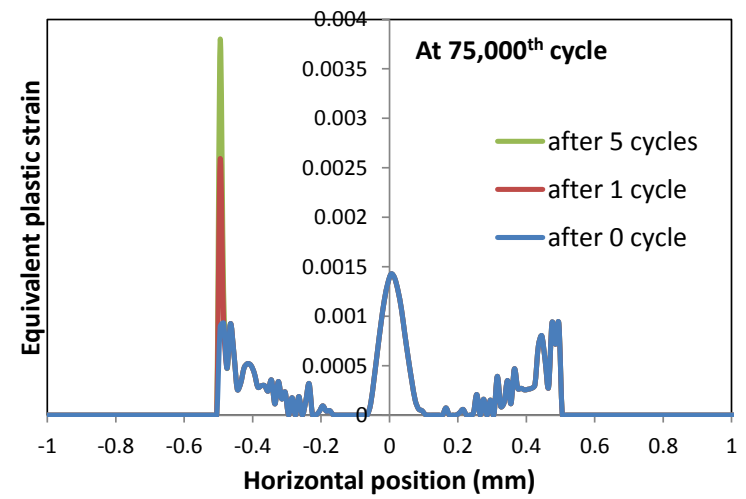

(c)

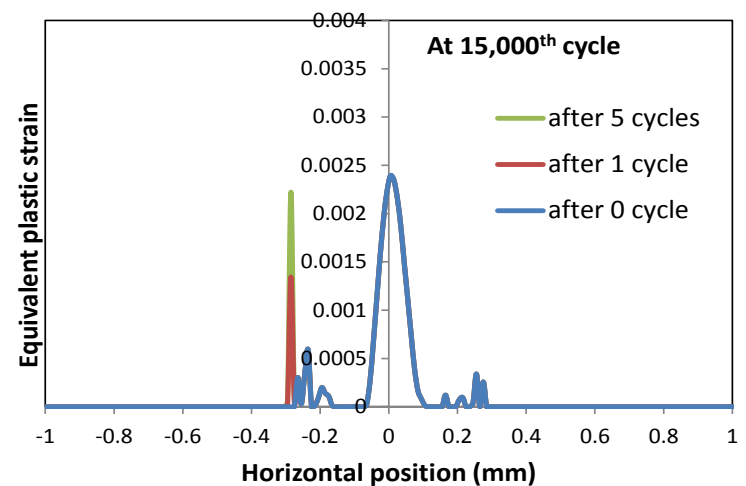

(b)

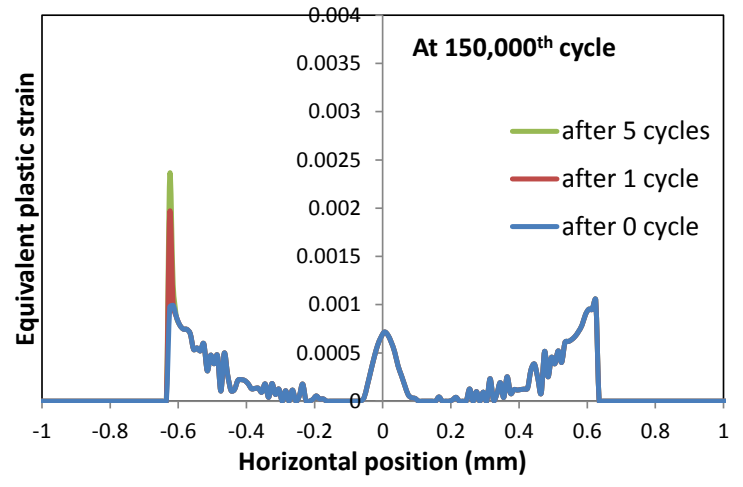

(d) 


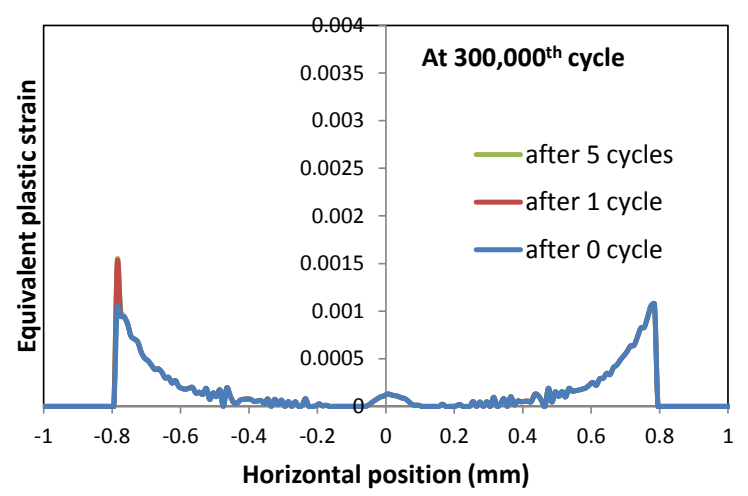

(e)

Fig. 6. FE-predicted equivalent plastic strain evolution for the gross-sliding case $\left(2 \delta_{a p p}=120 \mu \mathrm{m}, P=1000 \mathrm{~N}\right)$ after one and five applied cyclic displacements at a specific geometrical wear shape at a given $n^{\text {th }}$ cycle; a) $0^{\text {th }}$ cycle, b) $15,000^{\text {th }}$ cycle, c) $75,000^{\text {th }}$ cycle, d) $150,000^{\text {th }}$ cycle, and e) $300,000^{\text {th }}$ cycle (wear effect is suppressed during the applied cyclic displacement).

\subsubsection{Partial-slip case}

Figs. 7(a-e) show the predicted plastic strain for the partial-slip case at the $0^{\text {th }}, 15,000^{\text {th }}, 75,000^{\text {th }}$, $150,000^{\text {th }}$, and $300,000^{\text {th }}$ cycles. No plasticity is predicted at the $0^{\text {th }}$ cycle. At the $15,000^{\text {th }}$ cycle (Fig. $7 \mathrm{~b}$ ), plasticity accumulation of up to $0.2 \%$ of strain is predicted after five additional fretting cycles are applied. The value of the predicted equivalent plastic strain increases to $0.125 \%$ of strain after one additional cycle is simulated. Similar trends are predicted at different numbers of cycles. For the $75,000^{\text {th }}$ cycle (Fig. 7c), the predicted equivalent plastic strain increased from $6 \%$ to $9 \%$ of strain after five additional fretting cycles. An increase from $35 \%$ to $45 \%$ of equivalent plastic strain was predicted for the $150,000^{\text {th }}$ cycle (Fig. 7d). An increase of up to $200 \%$ of strain was predicted for the equivalent plastic strain at the $300,000^{\text {th }}$ cycle (Fig. 7e). Most of the increases in plastic strain were predicted to occur at the stick-slip interface, and were expected to increase with every additional fretting cycle.

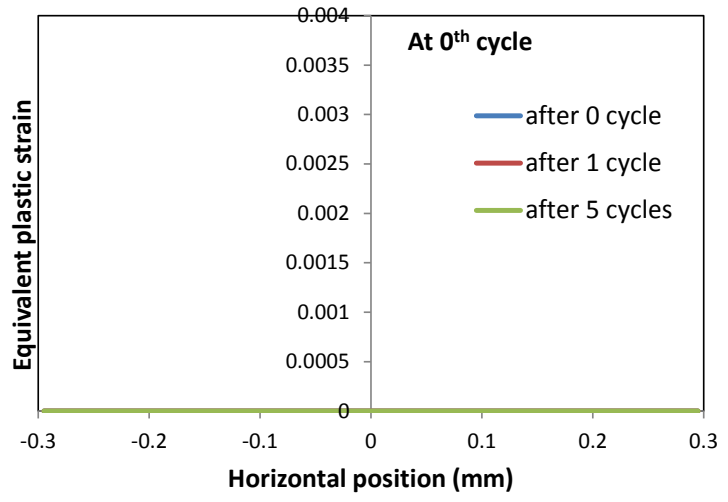

(a)

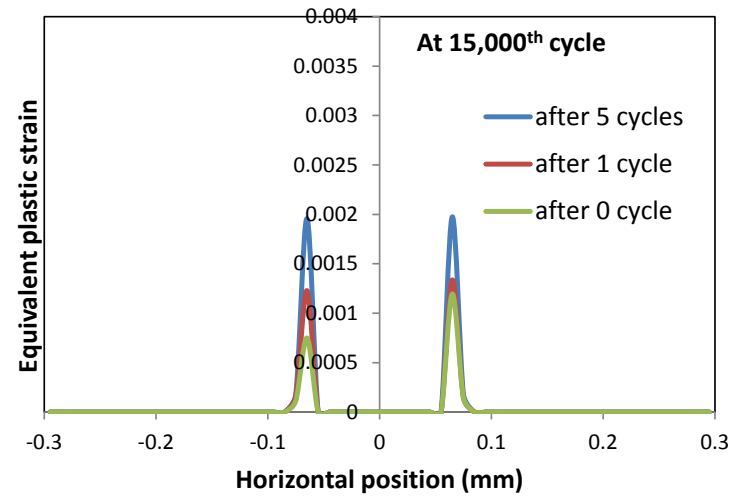

(b) 


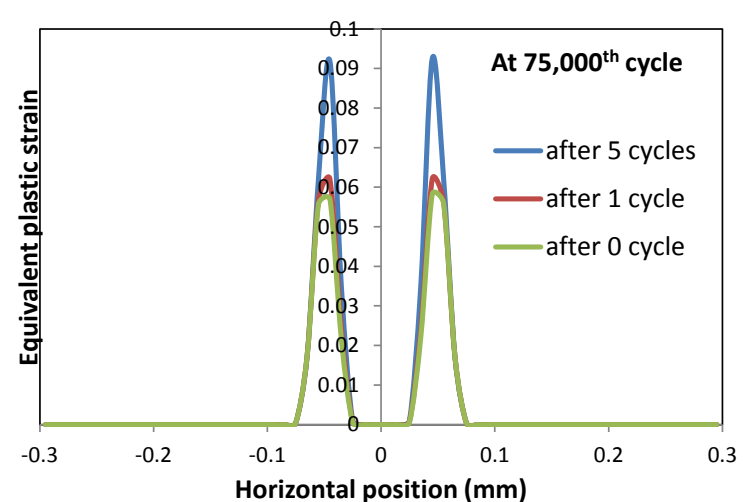

(c)

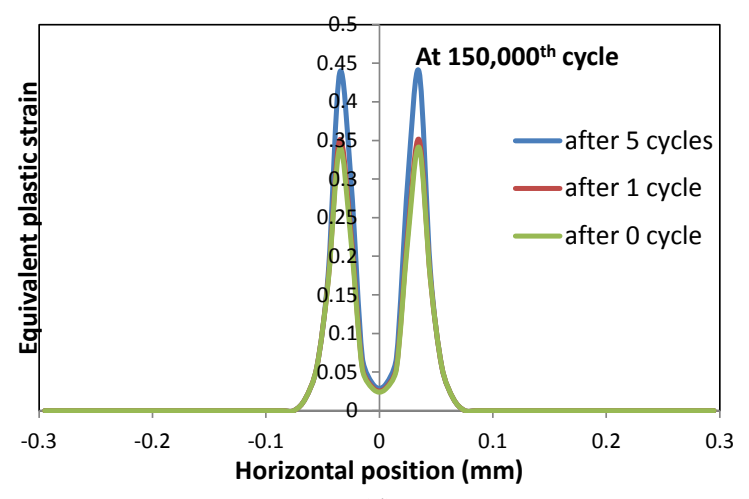

(d)

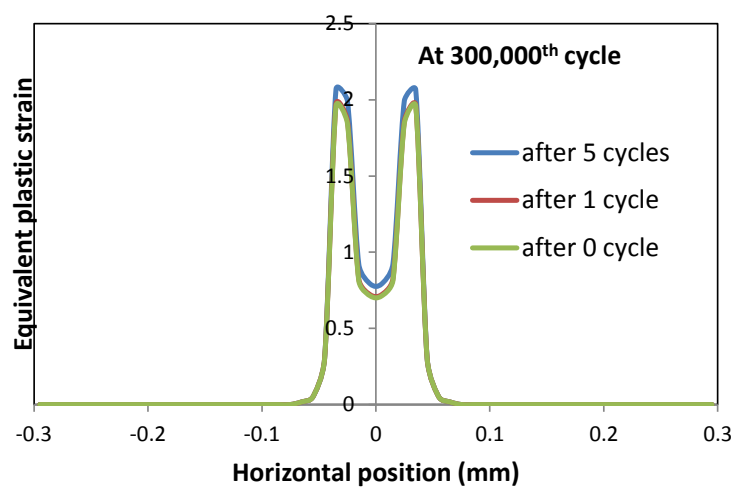

(e)

Fig. 7. FE-predicted equivalent plastic strain evolution for the partial-slip case $\left(2 \delta_{a p p}=50 \mu \mathrm{m}, P=1000 \mathrm{~N}\right)$ after one and five applied cyclic displacements, at a specific geometrical wear shape at a given $\mathrm{n}^{\text {th }}$ cycle: a) $0^{\text {th }}$ cycle, b) $15,000^{\text {th }}$ cycle, c) $75,000^{\text {th }}$ cycle, d) $150,000^{\text {th }}$ cycle, and e) $300,000^{\text {th }}$ cycle (wear effect is suppressed during the applied cyclic displacement).

\section{Discussion}

\subsection{Gross-sliding}

The predicted equivalent plastic strain using the new extension model provides insight into the magnitude of the plasticity accumulation experienced by the fretting contact without the overlapping material removal effect from the wear model. However, the model is based on the captured state variables and the geometrical shape at a particular cycle generated from the initial wear model. This allows the effect of wear to be explicitly incorporated.

As shown in the predicted equivalent plastic strain in the new extension model for the gross-sliding case (Fig. 6), the value of the predicted plastic strain generally tends to saturate as the number of additional cycles increases. The contact experienced material hardening as it is plastically deformed, causing subsequent cycles to produce less plasticity. At the $0^{\text {th }}$ cycle, a significant increase in plasticity was generated after one additional fretting cycle. This was due to high contact pressure at the centre, causing the surface to yield in shear as the contact is completely in sliding, which occurred without the effect of wear. This suggests that a significant amount of plasticity was initially generated in the central contact region. 
As the number of fretting cycles increases, and the wear effect causes changes in shape and increases in contact conformity, the accumulation of plasticity at the centre no longer occurs. This is due to less shear yield plasticity generated at the centre caused by lower contact pressure distribution. Now, the plasticity is predicted at the contact edge due to the ploughing effect (Figs. 6(b-e)). The amount of plastic strain per additional cycle is higher for the first cycle compared to the fifth cycle.

Comparing the results at the $15,000^{\text {th }}$ cycle (Fig. 6b) with the $75,000^{\text {th }}$ cycle (Fig. 6c), the plastic strain accumulation is higher at the $75,000^{\text {th }}$ cycle with additional fretting cycles. As the wear scar edge developed, the tendency to generate edge plasticity increased in the early fretting cycles. However, as the pressure drops with additional fretting wear (at the $150,000^{\text {th }}$ cycle (Fig. 6d) and the $300,000^{\text {th }}$ cycle (Fig. 6e), the edge plasticity decreases since the overall pressure distribution is decreasing (Fig. 4a). This reduces the predicted equivalent plastic strain increment with additional fretting cycles in the $150,000^{\text {th }}$ and $300,000^{\text {th }}$ cycle cases. In addition, there is not a meaningful increase in equivalent plastic strain predicted after the first additional cycle at the higher cycles $\left(150,000^{\text {th }}\right.$ and $300,000^{\text {th }}$ cycle). Once the material at the edge hardens, the low-pressure distributions are not able to yield the edge.

This prediction can potentially explain the $W$-shaped wear scar observed in the fretting test conducted by [10 \& 20]. At a low number of cycles, a large magnitude of predicted plastic accumulation in the central region of the wear scar can cause a significant amount of wear (Fig. 8). This will initially generate a $U$-shaped wear scar. The next stage is the generation of the ploughing effect at the $U$-shaped wear scar. This effect causes an accumulation of plasticity at the edge of the wear scar. By assuming that the area with plasticity accumulation will have a higher wear rate than the rest of the contact region, a slightly deeper wear scar was developed at the edge, rather than in the region without plasticity (Fig. 8). This causes $W$-shaped wear. With further advancement of fretting cycles, the reduced contact pressure is not capable of generating edge plasticity, thus maintaining the $W$ shape (Fig. 8). 


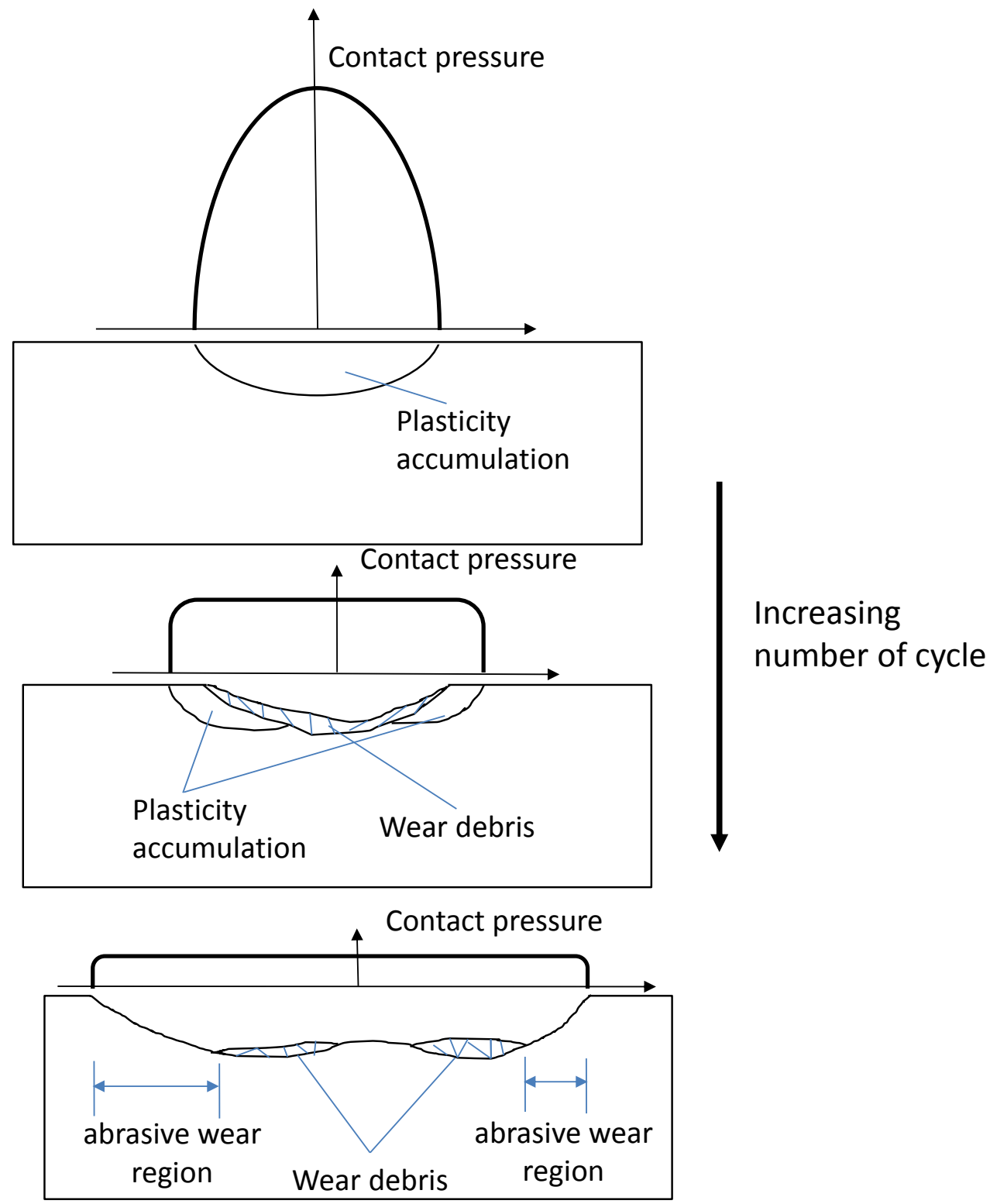

Fig. 8. Schematic view of the plasticity-induced wear mechanism with the changes in pressure reduction showing the region of plasticity accumulation in the gross-sliding condition.

\subsection{Partial-slip}

In contrast to the gross-sliding case, no plasticity increment was predicted at the $0^{\text {th }}$ cycle with an additional fretting cycle in the partial-slip case (Fig. 7a). The low applied displacement does not generate sufficient sliding to shear yield the surface; thus, no increment in equivalent plastic strain was predicted. Based on all of the new extension model results, except those obtained at the $0^{\text {th }}$ cycle, the plastic strain will be accumulated in the additional fretting cycle (Figs. 7(b-e)). The plasticity continues to increase even after five additional cycles owing to high peak pressure at the stick-slip interface. The value of the increment is higher at later fretting wear cycles 
due to higher pressure distributions. It can be assumed that in the partial-slip case, for large numbers of wear cycles where the peak pressure has been developed at the stick-slip interface, a significant amount of plastic strain will be generated for every contact pass it experiences. This occurs without the effect of wear and reveals the amount of plasticity accumulation that the stick-slip interface experiences during fretting.

The assumption can then be made that this amount of plasticity accumulation contributes to either the wear or the fatigue of the material. Fig. 9 shows the SWT fatigue parameter for the new extension model at the $75,000^{\text {th }}, 150,000^{\text {th }}$, and $300,000^{\text {th }}$ cycles. The SWT [21] fatigue parameter is based on a combination of the high cycle fatigue (Basquin), and low-cycle fatigue (Coffin-Manson), strain life equations. Since strain life equations do not include the mean stress effect on fatigue life, an additional maximum stress term, $\sigma_{\max }$, was used to allow the effect of mean stress on fatigue life to be considered.

$$
\mathrm{SWT}=\sigma_{\max } \frac{\Delta \varepsilon}{2}=\frac{\sigma_{f}^{\prime 2}}{E}\left(2 N_{f}\right)^{2 B}+\sigma_{f}^{\prime} \varepsilon_{f}^{\prime}\left(2 N_{f}\right)^{B+C},
$$

where $\sigma_{f}^{\prime}$ and $B$ are the fatigue strength coefficient and exponent, respectively, and $\varepsilon_{f}^{\prime}$ and $C$ are the fatigue ductility coefficient and exponent, respectively. $E$ is Young's modulus and $N_{f}$ is the number of cycles required to initiate a crack of a given length.

It can be seen from the SWT prediction distribution for the case of the $75,000^{\text {th }}, 150,000^{\text {th }}$, and $300,000^{\text {th }}$ cycle extension model that there is no significant change in the value of SWT after five additional fretting cycles (Figs. 9(a-c)). Even after the strain had increased as much as 0.1 for every additional cycle, the SWT value remained nearly the same. In addition, the SWT prediction at the $75,000^{\text {th }}$ and $150,000^{\text {th }}$ cycle keeps decreasing with additional cycles (Fig. 9d). This suggests that plastic strain accumulation does not meaningfully affect fatigue behaviour.

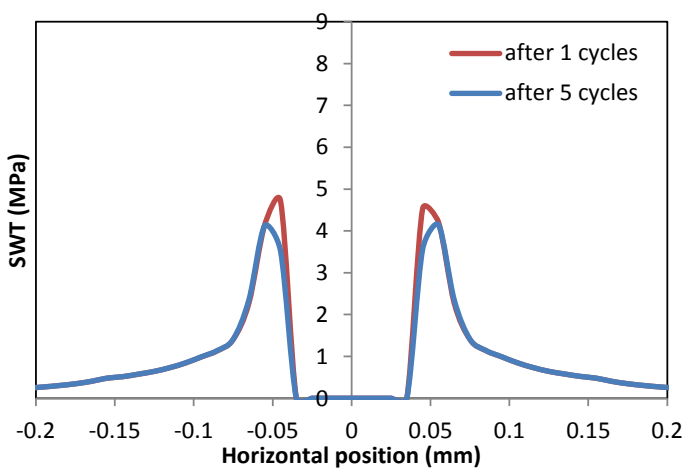

(a)

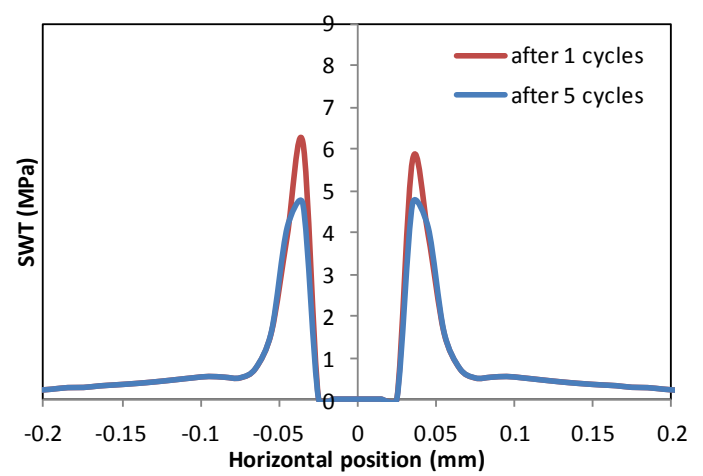

(b) 


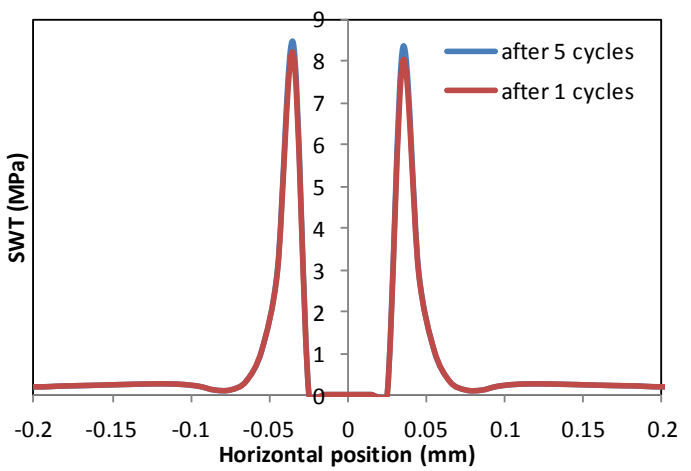

(c)

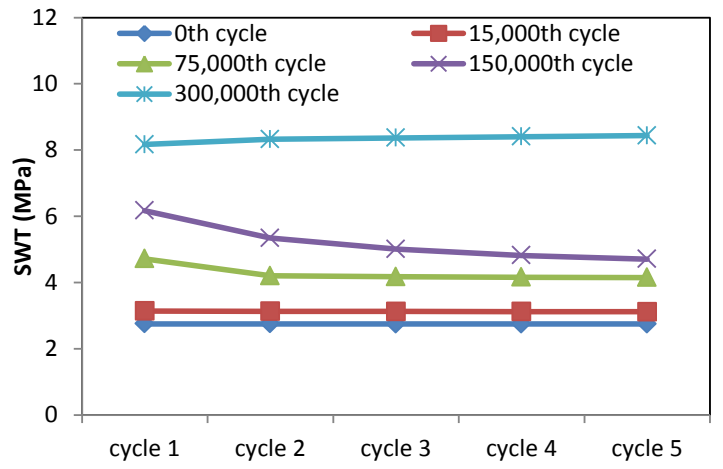

(d)

Fig. 9. SWT fatigue parameter prediction for the subsequent additional five cycle remodel analysis for surface profiles at the: a) $75,000^{\text {th }}$ cycle, b) $150,000^{\text {th }}$ cycle, c) $300,000^{\text {th }}$ cycle, and d) maximum SWT evolution for all the surface profiles modelled (partial-slip case: $2 \delta_{a p p}=50 \mu \mathrm{m}, P=1000 \mathrm{~N}$ ).

In order to understand the contribution of stress and strain to the SWT fatigue parameter, a stress-strain plot of the tangential and shear components located at the maximum value of SWT is presented in Figs. 10(a-b) for the $150,000^{\text {th }}$ cycle case and Figs. $10(\mathrm{c}-\mathrm{d})$ for the $300,000^{\text {th }}$ cycle case. For the $150,000^{\text {th }}$ cycle case, with the additional five cycles modelled, there were no significant changes in the shape of the stress-strain loops for the tangential and shear components. The loops show that the material had undergone a plastic shakedown rather than plastic ratchetting. For every additional cycle, plastic strain was generated and accumulated, but the overall strain range remained nearly the same. This explains that there were no significant changes in SWT prediction, but there was very high plastic accumulation. For the $300,000^{\text {th }}$ cycle case (Figs. 10 (c-d)), it can be seen that the shear stress-strain loops (Fig. 10d) did experience increments of strain (ratchetting) along with plastic-shakedown-type plasticity accumulation.

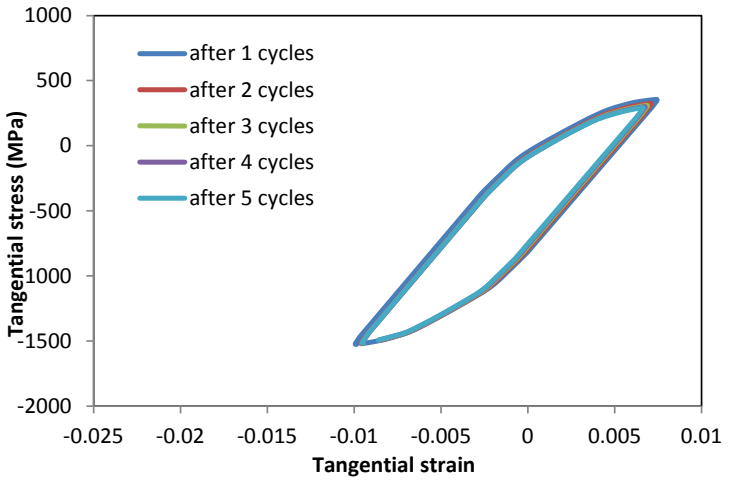

(a)

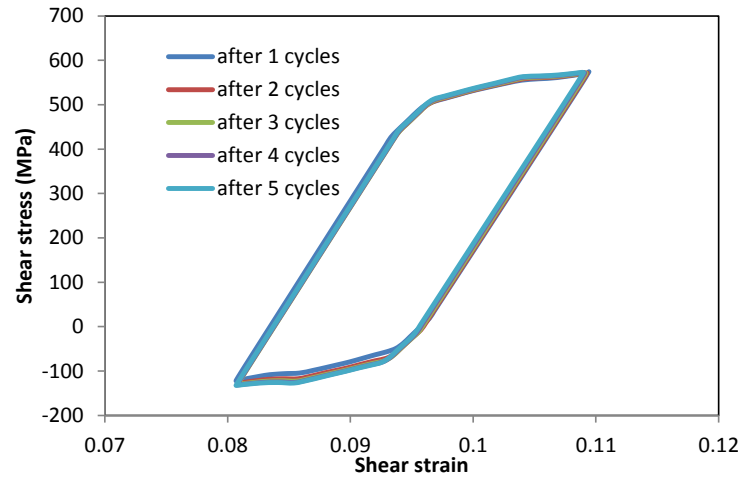

(b) 


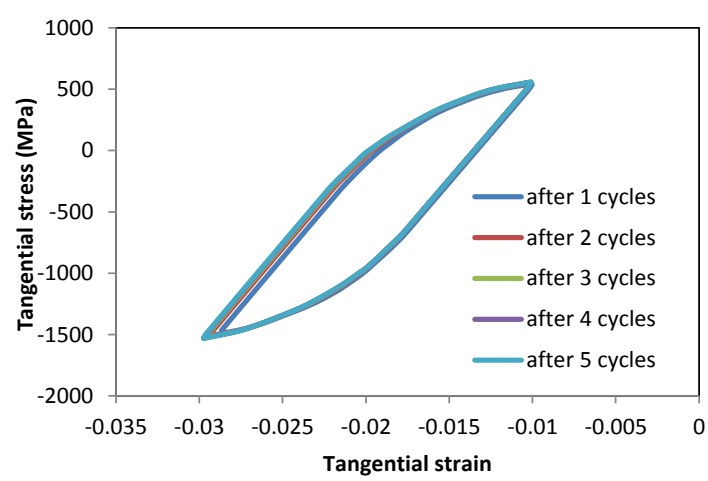

(c)

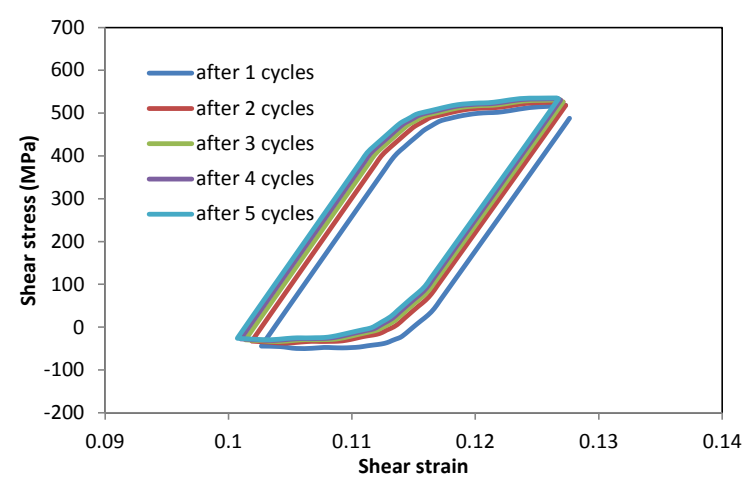

(d)

Fig. 10. Stress and strain loops for the $150,000^{\text {th }}$ cycle case: a) tangential component, b) shear component; Stress and strain loops for the $300,000^{\text {th }}$ cycle case: c) tangential component, d) shear component (partial-slip case: $2 \delta_{a p p}=50 \mu \mathrm{m}, P$ $=1000 \mathrm{~N})$.

Therefore, the results show that the accumulated plastic strain contributes to the wear of the material at the stick-slip interface rather than towards the contact fatigue. A similar mechanism of wear by plasticity accumulation (as explained in the gross-sliding case) might occur and create a high-wear regime at the stick-slip interface. Evidence from literature shows that there are a number of cases where Ti-6Al-4V partial-slip fretting tests experience crack mouth widening at the stick-slip interface [6 \& 10] (Fig. 11). This significant crack mouth widening can be associated with plasticity-induced wear at the stick-slip interface.

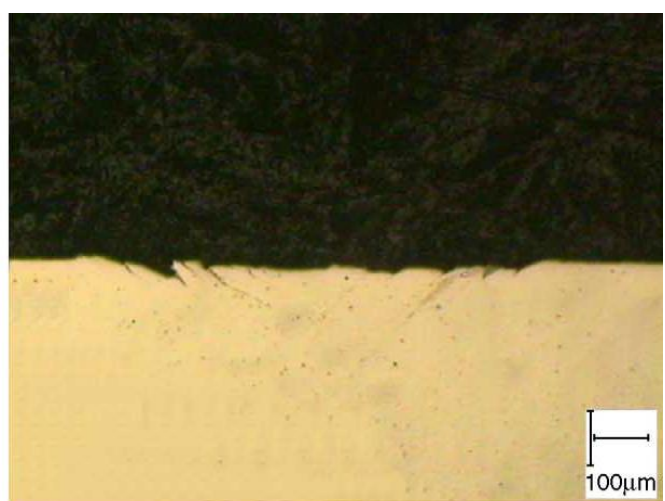

(a)

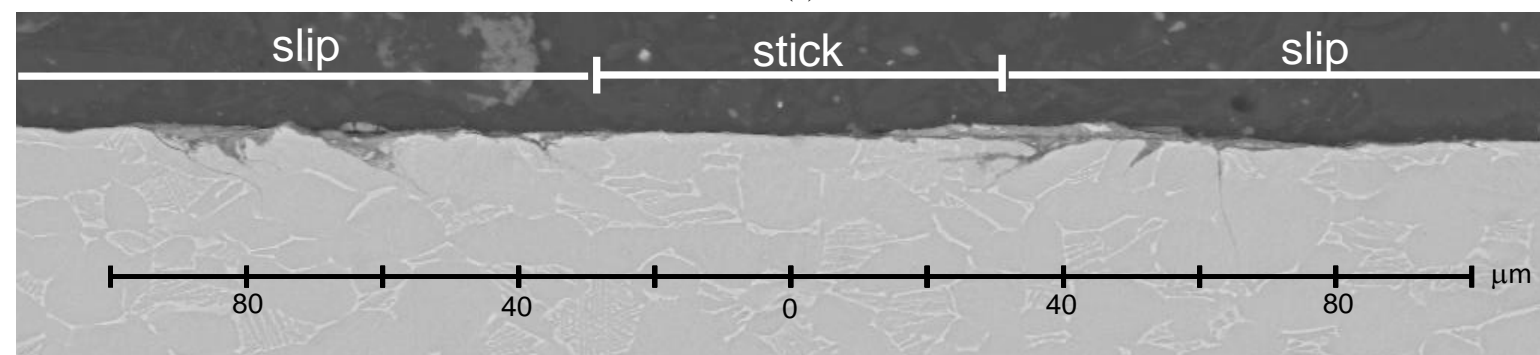

(b)

Fig. 11. Cross-section of Ti-6Al-4V partial-slip flat specimen wear scar showing crack mouth widening; a) from [6], $(P=1000$ $\mathrm{N}, 20 \mathrm{~mm}$ diameter indenter, 100,000 cycles, $25 \mu \mathrm{m}$ applied displacement), and b) from [10] ( $P=1000 \mathrm{~N}, 6 \mathrm{~mm}$ diameter indenter, 100,000 cycles, $25 \mu \mathrm{m}$ applied displacement). 
Previously, it had been predicted that plasticity caused ratchetting in partial-slip fretting wear modelling [10] because of the change in geometry caused during simulated wear. This paper discovered that plasticity accumulation is significant in the partial-slip case at later cycles, and is significant in the early cycles in the grosssliding case. Furthermore, the interpretation of the wear model throughout the contact region can be improved by using multiple wear rates across the contact to simulate $W$-shaped wear in gross-sliding.

\section{Conclusions}

In this study, a novel finite element modelling method was developed to investigate the accumulation of plastic strain in fretting wear without the active interaction of a wear model. The model was based on the conditions generated from a wear modelling analysis, which was conducted separately at the beginning of the experiment. This new method preserved the state conditions generated during the initial wear modelling process, and allowed for the prediction of plastic accumulation of the non-wear fretting cycle to be conducted. The following conclusions can be drawn from this study:

- For the gross-sliding case:

- The plasticity accumulation was predicted to saturate as the material hardened under additional fretting cycle. A significant accumulation of plastic strain occurred at the central region of the contact due to a high contact pressure distribution that occurs before the wear effect activates. As the contact is worn and the contact pressure distribution is reduced, no central plasticity accumulation was predicted.

- After a worn profile was generated, the wear scar edge plasticity was predicted to accumulate due to the ploughing effect. However, the amount of plasticity accumulation saturates with additional fretting cycles. At higher cycles with lower pressure distributions, a lower amount of edge wear plasticity was predicted.

- The prediction of plasticity accumulation in the gross-sliding case can be used to support the development of a $W$-shaped wear scar in gross-sliding fretting wear of Ti-6Al-4V.

- For the partial-slip case:

- In contrast to the gross-sliding case, no plasticity accumulation was predicted at the $0^{\text {th }}$ cycle due to there being no significant amount of sliding to shear yield the contact surface.

- Once the peak pressure was generated at the stick-slip interface, a significant amount of plasticity accumulation with additional fretting cycle was predicted. The incremental amount is more significant at a higher number of cycles, as the peak pressure developed by stick-slip wear.

- The plasticity accumulation does not meaningfully contribute to the fatigue life due to the similar stress-strain loops predicted from the new model. The plasticity accumulation arises from the plastic shakedown behaviour in the contact region. 
- The widening of the crack mouth observed experimentally in partial-slip fretting of Ti-6Al-4V from literature might be associated with the accumulation of the plastic strain at the stick-slip interface, which generates wear and widening of the crack mouth.

\section{Acknowledgements}

The authors wish to thank Universiti Tun Hussein Onn Malaysia RACE 1441, E15501, for their support of the research, which was carried out at the University of Nottingham.

\section{References}

[1] Varenberg, M., Etsion, I. \& Halperin, G. (2004) Slip index: a new unified approach to fretting. Tribology Letters, $17,569-573$.

[2] Cattaneo, C. (1938) Sul contatto di due corpi elastici: distribuzion locale degli sforzi, Reconditi dell Academia nazionale dei Lincei 27, 342-348, 434-436, 474-478.

[3] Mindlin, R. D. (1949) Compliance of elastic bodies in contact, Journal of Applied Mechanics-Transactions of the ASME 16 (3), 259-268.

[4] Johnson, K. L. (1985) Contact Mechanics, Cambridge University Press, Cambridge.

[5] Maouche, N., Maitournam, M. H. \& Van, K. D. (1997) On a new method of evaluation of the inelastic state due to moving contacts. Wear, $203,139-147$.

[6] Fouvry, S., Duó, P. \& Perruchaut, P. (2004) A quantitative approach of Ti-6Al-4V fretting damage: friction, wear and crack nucleation. Wear, 257, 916-929.

[7] McColl, I. R., Ding, J. \& Leen, S. B. (2004) Finite element simulation and experimental validation of fretting wear. Wear, $256,1114-1127$.

[8] Paulin, C., Fouvry, S. \& Meunier, C. (2008) Finite element modelling of fretting wear surface evolution: Application to a Ti-6A1-4V contact. Wear, 264 (1-2), 26-36.

[9] Ding, J., Leen, S. B. \& McColl, I. R. (2004) The effect of slip regime on fretting wear-induced stress evolution. International Journal of Fatigue, 26, 521-531.

[10] Mohd Tobi, A. L., Ding, J., Bandak, G., Leen, S. B. \& Shipway, P. H. (2009) A study on the interaction between fretting wear and cyclic plasticity for Ti-6Al-4V. Wear, 267, 270-282.

[11] Fei Shen, Weiping Hu, Voyiadjis, G. Z., \& Qingchun Meng. (2015) Effects of fatigue damage and wear on fretting fatigue under partialslip condition. Wear, 338-339, 394-405.

[12] Basseville, S. \& Cailletaud, G. (2015) An evaluation of the competition between wear and crack initiation in fretting conditions for Ti6Al-4V alloy. Wear, 328-329, 443-455.

[13] Hu, Z., Lu, W., Thouless, M.D., \& Barber, J.R. (2016) Effect of plastic deformation on the evolution of wear and local stress fields in€ fretting. Int. J. of Solids and Structures, 8, 1-8.

[14] Gandiolle, C., Fouvry, S. \& Charkaluk, E. (2016) Lifetime prediction methodology for variable fretting fatigue loading: Plasticity effect. International Journal of Fatigue, 92 (2), 531-547.

[15] McCarthy, O. J., McGarry, J. P. \& Leen, S. B. (2014) Micro-mechanical modelling of fretting fatigue crack initiation and wear in Ti-6Al4V. International Journal of Fatigue, 62, 180-193.

[16] Song, Y., Dai, Z. \& Xue, Q. (2014) Entropy generation related to plastic deformation in fretting friction. Wear, 315 (1-2), 42-50.

[17] Garcin, S., Fouvry, S. \& Heredia, S. (2015) A FEM fretting map modeling: Effect of surface wear on crack nucleation. Wear, 330-331, $145-159$.

[18] Medina S, Olver A.V. (2002) An analysis of misaligned spline couplings. Journal of Engineering Tribology, 216, 269-279. 
[19] Benedetti, M. \& Fontanari, V. (2004) The effect of bi-modal and lamellar microstructures of Ti-6Al-4V on the behaviour of fatigue cracks emanating from edge-notches. Fatigue \& Fracture of Engineering Materials \& Structures, 27, 1073-1089.

[20] Magaziner, R. S., Jain, V. K. \& Mall, S. (2004) Wear characterization of Ti-6Al-4V under fretting-reciprocating sliding conditions. Wear, 264, 1002-1014.

[21] Smith, K. N., Watson P., Topper T. H. (1970) A stress-strain function for the fatigue of metals. Journal of Materials, 15, 767-778. 